\title{
Possible action mechanism for curcumin in pre-cancerous lesions based on serum and salivary markers of oxidative stress
}

\author{
Balwant Rai1), Jasdeep Kaur $^{1)}$, Reinhilde Jacobs ${ }^{2,3)}$ and Jaipaul Singh ${ }^{4)}$ \\ ${ }^{1)}$ School of Dentistry, Oral Pathology and Maxillofacial Surgery, Catholic University Leuven, \\ Leuven, Belgium \\ ${ }^{2}$ Department of Periodontology, School of Dentistry, Oral Pathology and Maxillofacial Surgery, \\ Catholic University Leuven, Leuven, Belgium \\ ${ }^{3)}$ Oral Imaging Center, School of Dentistry, Oral Pathology and Maxillofacial Surgery, \\ Catholic University Leuven, Leuven, Belgium \\ 4)University of Central Lancashire, Lancashire, UK
}

(Received 1 October 2009 and accepted 26 February 2010)

\begin{abstract}
Extensive research within the past halfcentury has indicated that curcumin (diferuloylmethane), a yellow pigment in curry powder, exhibits anti-oxidant, anti-inflammatory, and proapoptotic activities. We investigated whether the antipre-cancer activities assigned to curcumin are mediated through an anti-oxidant and DNA-protecting mechanism. Patients with oral leukoplakia, oral submucous fibrosis or lichen planus, and healthy individuals ( $n=25$ for each group) aged 17-50 years were selected. Salivary and serum oxidative markers such as malonaldehyde (MDA), 8hydroxydeoxyguanosine (8-OHdG), vitamins $\mathrm{C}$ and $\mathrm{E}$ were measured just prior to the intake of curcumin, after one week of curcumin intake and following clinical cure of precancerous lesions. Serum and salivary vitamins $\mathrm{C}$ and $\mathrm{E}$ showed increases, while MDA and 8-OHdG levels showed decreases in patients with oral leukoplakia, submucous fibrosis and lichen planus after intake of curcumin for all categories of precancerous lesions. The changes in these values were observed to be statistically significant after clinical cure of the disease $(P<0.05)$. The five-point rating scale
\end{abstract}

Correspondence to Dr. Balwant Rai, Oral Imaging Center, School of Dentistry, Oral Pathology and Maxillofacial Surgery, Catholic University Leuven, Kapucijnenvoer 7, 3000 Leuven, Belgium Tel: +32-484466705

E-mail: drbalwantraissct@ rediffmail.com for pain, as well as lesion size in oral leukoplakia, submucous fibrosis and lichen planus, improved significantly $(P<0.05)$. In addition, in submucous fibrosis, mouth opening $(P<0.05)$ recovered significantly. In oral leukoplakia, submucous fibrosis and lichen planus, the levels of serum and salivary vitamins $\mathrm{C}$ and $\mathrm{E}$ increased significantly, while MDA and 8-OHdG levels decreased after 131(15), 211(17), and 191(18) days, respectively. Values for serum and salivary vitamins $C$ and $E$ showed a significant decrease in oral leukoplakia, submucous fibrosis and lichen planus, in contrast to healthy individuals, but increased significantly in all groups subsequent to curcumin administration after clinical cure of lesions. Based on these results, we can conclude that curcumin mediates its anti-pre-cancer activities by increasing levels of vitamins $\mathrm{C}$ and $\mathrm{E}$, and preventing lipid peroxidation and DNA damage. (J Oral Sci 52, 251-256, 2010)

Keywords: curcumin; antioxidant; precancerous lesions; serum; salivary; anti-pre-cancer.

\section{Introduction}

Oral cancer is the sixth most common form of cancer worldwide (1). Its incidence is particularly high in India, other Asian countries, and in certain places in the Western hemisphere, e.g., parts of France and Brazil, where smoking 
and alcohol consumption are major risk factors. In India, the chewing and smoking of tobacco products in various forms is primarily responsible for the high incidence. The World Health Organization (WHO) has estimated that $90 \%$ of oral cancers in India among men are attributable to chewing and smoking habits (2). About $48.2 \%$ of cancers in men and $20.5 \%$ of cancers in women are related to tobacco, a major proportion of which is in the oral cavity, pharynx, larynx, esophagus (74.7\%), while lung cancers account only for $15 \%$. Control of cancers of the head and neck, lung, cervix and breast, which account for 50-55\% of the cancer load in India, will thus have a measurable effect on the incidence of cancer (3).

Oral squamous cell carcinoma develops through a multistep process of genetic, epigenetic and metabolic changes resulting from exposure to carcinogens (4). The initial presence of a precursor subsequently developing into cancer is well established in oral cancer (5). Oral leukoplakia and submucous fibrosis are two major precancerous lesions, but only $8-10 \%$ of these lesions ultimately become malignant (6). The ability to clinically predict malignant transformation is limited and routine histopathological diagnosis has limited prognostic value. The presence of epithelial dysplasia is an important parameter used in the prognostication of leukoplakia. However, there are limitations in its usage; the diagnosis is essentially subjective, all lesions exhibiting dysplasia do not eventually become malignant and some may even regress, and carcinoma can develop from lesions in which epithelial dysplasia was not diagnosed in previous biopsies (5). Therefore, it is necessary to develop other methods for predicting the malignant potential of pre-malignant lesions and preventive measures (7).

Free radical-mediated lipid peroxidation is involved in various cancers, and several studies have described the role of free radicals in oral cancers. Low salivary lipid peroxidation products such as malonaldehyde (MDA) and 8-hydroxydeoxyguanosine $(8-\mathrm{OHdG})$ have also been reported in oral cancer (8). Increases in lipid peroxidation products and decreases in antioxidant activity in cancer have been reported in the literature $(9,10)$, and randomized controlled trials have shown that antioxidant (vitamins $\mathrm{C}$ and $\mathrm{E}$ ) supplementation may be beneficial in the prevention of cancer $(11,12)$.

Various research over the past half-century has indicated that curcumin (also called diferuloylmethane), a yellow coloring agent present in turmeric, is an antioxidant more potent than $\alpha$-tocopherol (13). Curcumin has been linked with the suppression of mutagenesis; and has been used as a chemopreventive agent in a wide variety of cancers, including those of the colon, breast, prostate, esophagus, lung and oral cavity, as well as in inhibition of atherosclerosis and inhibition of viral and bacterial growth (14). It has been demonstrated that curcumin downregulates STE (khaini) or NNK-induced NF- $\mathrm{KB}$ and COX-2 in oral premalignant and cancer cells in vitro (15). In the present study, we hypothesized that curcumin may suppress or prevent oral pre-cancerous and cancerous lesions and conditions by inhibiting free radicals. To test this hypothesis, we examined the effects of curcumin in patients with leukoplakia, oral submucous fibrosis and lichen planus by measuring salivary and serum levels of MDA, 8-OHdG, and vitamins $\mathrm{C}$ and $\mathrm{E}$, before and after curcumin administration.

\section{Materials and Methods}

Twenty-five patients [male (M):female (F), 13:12] with oral leukoplakia, 25 patients (M:F, 11:14) with oral submucous fibrosis and 25 patients (M:F, 12:13) with lichen planus, as well as 25 normal healthy individuals (aged 17-50 years, attending Jain Diagnostic Centre, New Delhi, India) were selected. All diagnostic tests were evaluated for diagnosing oral pre-cancerous lesions. Each subject completed a medical and dental history questionnaire to determine the status of systemic disease, smoking, alcohol and drug history. Clinical examinations for systemic diseases, chronic diseases, oral and dental diseases were conducted, and patients were excluded if they had any history of systemic disease, chronic disease, dental disease, smoking habit, or alcohol and drug history.

Curcumin $1 \mathrm{~g}$ caplets $(900 \mathrm{mg}$ curcumin, $80 \mathrm{mg}$ desmethoxycurcumin, and $20 \mathrm{mg}$ bisdesmethoxycurcumin) were obtained from Sabinsa Corporation (Piscataway, NJ, USA).

Pain control and lesion healing were the 2 main clinical variables for evaluating cure of oral leukoplakia, oral lichen planus and oral submucous fibrosis. To measure pain, we used a visual scale analog ranging from 0.5 (very mild pain) to 5 (severe pain). For healing, we measured changes in lesion size, including ulcer size from baseline, while in oral submucous fibrosis, in addition to the above variables, change in mouth opening was considered. Final outcome was confirmed by clinical examination. Clinical and histopathological examinations were conducted, along with collection of serum and salivary samples prior to intake of curcumin. One week after clinical cure of disease, clinical examination was again performed along with collection of serum and salivary samples. Whole unstimulated saliva produced in a 5-min period (about 3 $\mathrm{ml}$ ) was collected, allowed to drain into a plastic container, and was centrifuged at $3,000 \times g$ at $4^{\circ} \mathrm{C}$ for $5 \mathrm{~min}$ in order to remove bacterial and cellular debris. Saliva samples were 
stored at $-80^{\circ} \mathrm{C}$ until analysis. Blood samples were collected into vacutainer tubes. Blood was centrifuged at $1,700 \times g$ for $10 \mathrm{~min}$ and plasma was separated. Plasma was stored at $-80^{\circ} \mathrm{C}$ until analysis was performed. Serum and salivary levels were assessed for MDA using thiobarbituric acid according to the method of Buege and Aust et al. (16). Concentrations of both vitamins were measured using liquid chromatography (17). Quantitative measurements of the oxidative DNA adduct 8-OHdG were performed according to the method of Toyokuni et al. (18). Briefly, saliva samples were centrifuged at $10,000 \times g$ for $10 \mathrm{~min}$ and the supernatant was used to determine 8-hydroxydeoxyguanosine $(8-\mathrm{OHdG})$ levels with a competitive ELISA kit (Japan Institute for the Control of Aging, Shizuoka, Japan). The determination range was 0.5-200 $\mathrm{ng} / \mathrm{ml}$. Serum 8-OHdG levels were measured in duplicate by competitive ELISA kit (OXIS; Portland, OR, USA) according to the manufacturer's instructions. The sensitivity of the method was $1 \mathrm{ng} / \mathrm{ml}$. All data were statistically analyzed using the SPSS statistical package (Version 13; Chicago, IL, USA). Data are expressed as means \pm standard deviation. Differences were analyzed for significance, using a one-way analysis of variance (ANOVA) test. Correlation assessment was performed by Spearman correlation analysis. Statistical significance was set at $P$ $<0.05$.

\section{Results}

The mean and median values of serum and salivary vitamins $\mathrm{C}$ and E showed increases, while MDA and 8OHdG levels showed decreases in oral leukoplakia, submucous fibrosis, lichen planus patients one week after intake of curcumin, as compared to before treatment in all precancerous patients. Furthermore, the values were statistically significant after clinical cure of disease (Table $1 ; P<0.05$; Figs. 1-8). Pain scores and size of lesion in oral leukoplakia, submucous fibrosis and lichen planus improved significantly $(P<0.05)$. In addition, in submucous fibrosis, mouth opening recovered significantly [24.64(3.2) to $39.4(3) \mathrm{mm} ; P<0.05]$. Oral leukoplakia, submucous fibrosis and lichen-planus were clinically cured after 131(15), 211(17), and 191(18) days, respectively. Serum and salivary vitamin $\mathrm{C}$ and $\mathrm{E}$ levels showed significant decreases, while MDA and 8-OHdG levels showed significant increases in oral leukoplakia, submucous fibrosis and lichen planus patients, as compared to healthy controls (Table $1 ; P<0.05$ ). Median salivary and serum MDA, 8$\mathrm{OHdG}$, and vitamin $\mathrm{C}$ and $\mathrm{E}$ levels were significantly different in precancerous patients before intake of curcumin and after clinical cure, and after 209 days in healthy subjects, although the differences were greater in precancerous patients (Figs. 1-8). Serum and salivary correlation analysis revealed strong and highly significant correlations for MDA, vitamins $\mathrm{C}$ and $\mathrm{E}$, and 8-OHdG in all groups $(\mathrm{r}=0.86, \mathrm{r}=0.67$ and $\mathrm{r}=0.76, P<0.001$, and $\mathrm{r}=0.67, \mathrm{r}=0.66$ and $\mathrm{r}=0.64, P<0.001$, respectively).

Table 1 Salivary and serum MDA, 8-OHdG, and vitamin C and E levels in oral leukoplakia, oral lichen planus and oral submucous fibrosis patients, and healthy controls prior to intake of curcumin, one week after curcumin intake, after clinical cure of oral precancerous lesions and after 209 days

\begin{tabular}{|c|c|c|c|c|c|c|c|c|}
\hline Participant group & $\begin{array}{l}\text { MDA } \\
\text { Salivary } \\
(\mu \mathrm{mol} / \mathrm{l})\end{array}$ & $\begin{array}{l}\text { Serum } \\
(\mu \mathrm{mol} / 1)\end{array}$ & $\begin{array}{l}\text { 8-OhdG } \\
\text { Salivary } \\
(\mathrm{ng} / \mathrm{ml})\end{array}$ & $\begin{array}{l}\text { Serum } \\
(\mathrm{ng} / \mathrm{ml})\end{array}$ & $\begin{array}{l}\text { Vitamin } C \\
\text { Salivary } \\
(\mu \mathrm{g} / \mathrm{l})\end{array}$ & $\begin{array}{l}\text { Serum } \\
(\mu \mathrm{g} / 1)\end{array}$ & $\begin{array}{l}\text { Vitamin } \mathbf{E} \\
\text { Salivary } \\
(\mu \mathrm{g} / 1)\end{array}$ & $\begin{array}{l}\text { Serum } \\
(\mu g / 1)\end{array}$ \\
\hline \multicolumn{9}{|c|}{ Prior to intake of curcumin (A) } \\
\hline Normal & $0.11(0.13)$ & $0.98(0.86)$ & $0.11(0.12)$ & $2.17(1.45)$ & $1.46(0.86)$ & $9.05(2.21)$ & $0.91(0.43)$ & $8.97(2.34)$ \\
\hline Oral lichen planus & $0.35(0.26)$ & $1.16(0.89)$ & $0.39(0.23)$ & $2.14(1.89)$ & $1.04(0.69)$ & $8.48(2.66)$ & $0.68(0.31)$ & $8.15(2.33)$ \\
\hline Oral leukoplakia & $0.36(0.17)$ & $1.23(0.56)$ & $0.34(0.24)$ & $2.13(1.12)$ & $1.08(0.98)$ & $8.78(3.12)$ & $0.65(0.31)$ & $8.01(1.23)$ \\
\hline $\begin{array}{l}\text { Oral submucous } \\
\text { fibrosis }\end{array}$ & $0.32(0.16)$ & $1.19(0.37)$ & $0.32(0.14)$ & $2.12(2.24)$ & $1.01(0.32)$ & $8.56(3.56)$ & $0.67(0.32)$ & $8.08(1.13)$ \\
\hline \multicolumn{9}{|l|}{ After 7 days } \\
\hline Normal & $0.09(0.11)$ & $0.95(0.56)$ & $0.09(0.12)$ & $2.01(1.11)$ & $1.67(0.89)$ & $9.08(2.66)$ & $0.98(0.43)$ & $8.99(2.35)$ \\
\hline Oral lichen planus & $0.29(0.24)$ & $1.08(0.67)$ & $0.34(0.23)$ & $2.04(1.96)$ & $1.28(0.67)$ & $8.98(4.67)$ & $0.70(0.33)$ & $8.35(3.14)$ \\
\hline Oral leukoplakia & $0.32(0.23)$ & $1.07(0.81)$ & $0.31(0.23)$ & $2.01(1.09)$ & $1.43(0.65)$ & $8.89(3.34)$ & $0.69(0.44)$ & $8.12(3.43)$ \\
\hline $\begin{array}{l}\text { Oral submucous } \\
\text { fibrosis }\end{array}$ & $0.28(0.21)$ & $1.16(0.89)$ & $0.29(0.13)$ & $2.05(2.02)$ & $1.23(0.54)$ & $8.88(3.67)$ & $0.68(0.34)$ & $8.16(2.32)$ \\
\hline \multicolumn{9}{|c|}{ After curing of lesions and 209 days in normal healty } \\
\hline Normal & $0.07(0.08)$ & $0.53(0.68)$ & $0.07(0.06)$ & $1.71(1.65)$ & $1.72(0.76)$ & $9.65(3.93)$ & $1.07(0.85)$ & $9.15(4.56)$ \\
\hline Oral lichen planus & $0.13(0.12)$ & $0.96(0.62)$ & $0.12(0.13)$ & $1.78(0.98)$ & $1.56(0.81)$ & $9.05(2.86)$ & $0.91(0.45)$ & $9.09(3.45)$ \\
\hline Oral leukoplakia & $0.13(0.12)$ & $0.97(0.56)$ & $0.12(0.09)$ & $1.88(1.67)$ & $1.54(0.89)$ & $9.09(3.86)$ & $0.96(0.45)$ & $8.99(4.67)$ \\
\hline $\begin{array}{l}\text { Oral submucous } \\
\text { fibrosis }\end{array}$ & $0.11(0.11)$ & $0.98(0.67)$ & $0.11(0.12)$ & $1.89(1.78)$ & $1.45(0.79)$ & $9.05(2.86)$ & $0.89(0.29)$ & $8.97(3.43)$ \\
\hline
\end{tabular}




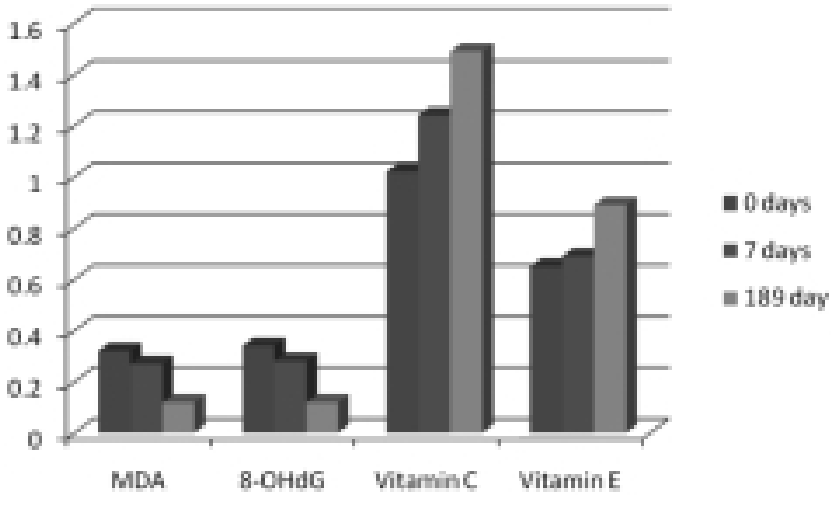

Fig. 1 Salivary MDA ( $\mu \mathrm{mol} / \mathrm{l}), 8-\mathrm{OHdG}(\mathrm{ng} / \mathrm{ml})$, and vitamin $\mathrm{C}(\mu \mathrm{g} / \mathrm{l})$ and $\mathrm{E}(\mu \mathrm{g} / \mathrm{l})$ levels prior to intake of curcumin, one week after curcumin intake, and after 189 days in healthy subjects.

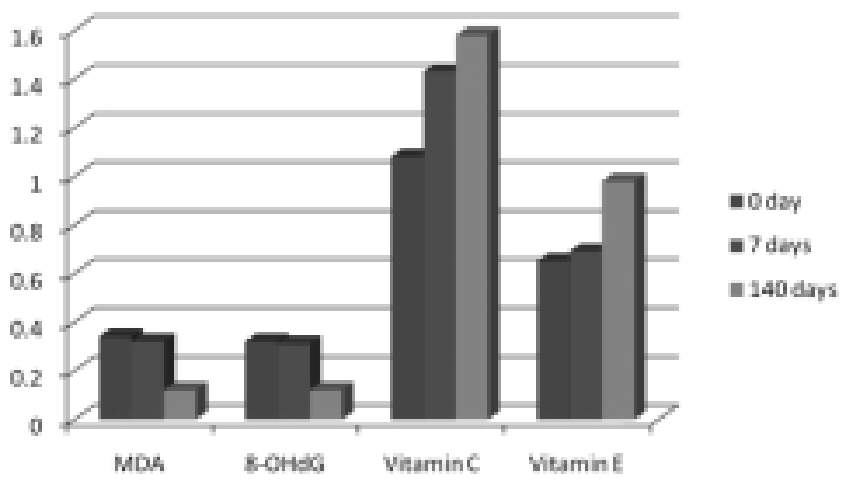

Fig. 2 Salivary MDA ( $\mu$ mol/l), 8-OHdG (ng/ml), and vitamin $\mathrm{C}(\mu \mathrm{g} / \mathrm{l})$ and $\mathrm{E}(\mu \mathrm{g} / \mathrm{l})$ levels prior to intake of curcumin, one week after curcumin, and after clinical cure of oral leukoplakia.

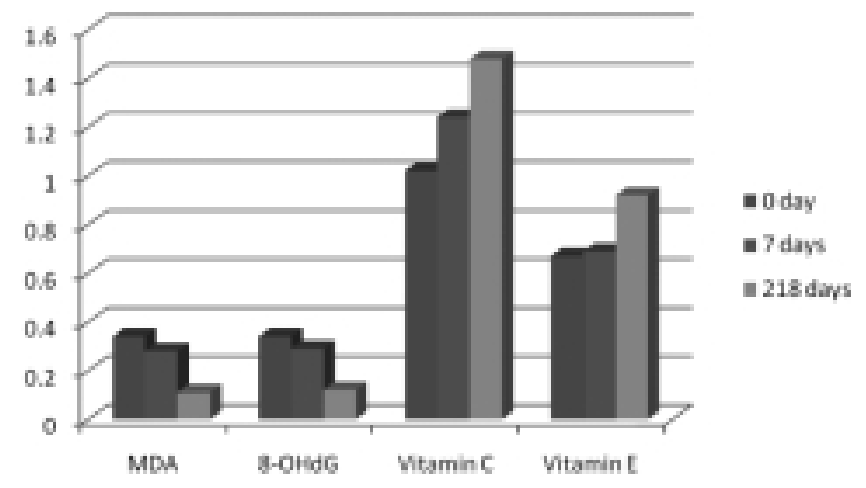

Fig. 3 Salivary MDA ( $\mu \mathrm{mol} / \mathrm{l}), 8-\mathrm{OHdG}(\mathrm{ng} / \mathrm{ml})$, and vitamin $\mathrm{C}(\mu \mathrm{g} / \mathrm{l})$ and $\mathrm{E}(\mu \mathrm{g} / \mathrm{l})$ levels prior to intake of curcumin, one week after curcumin intake, and after clinical cure of oral submucous fibrosis.

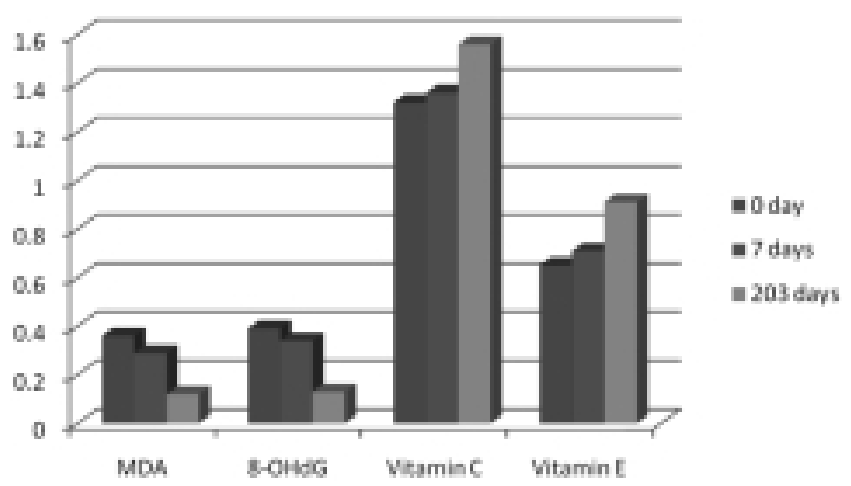

Fig. 4 Salivary MDA ( $\mu \mathrm{mol} / \mathrm{l}), 8-\mathrm{OHdG}(\mathrm{ng} / \mathrm{ml})$, and vitamin $\mathrm{C}(\mu \mathrm{g} / \mathrm{l})$ and $\mathrm{E}(\mu \mathrm{g} / \mathrm{l})$ levels prior to intake of curcumin, one week after curcumin intake, and after clinical cure of oral lichen planus.

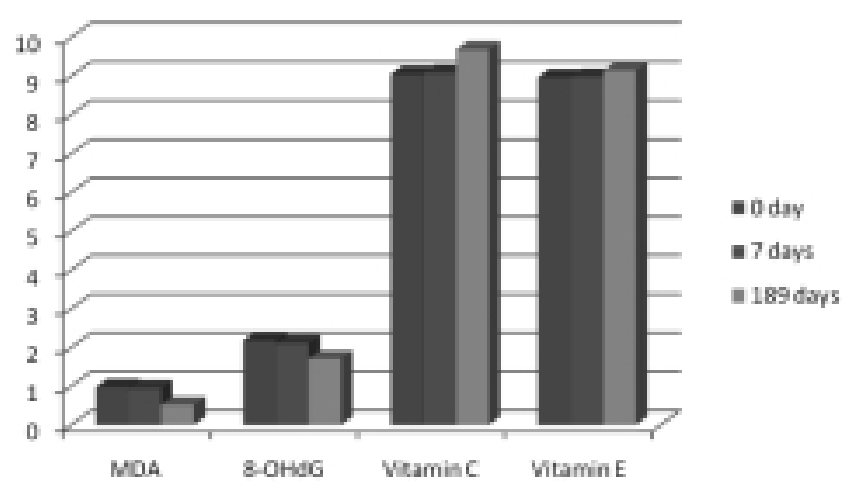

Fig. 5 Serum MDA ( $\mu \mathrm{mol} / \mathrm{l}), 8-\mathrm{OHdG}(\mathrm{ng} / \mathrm{ml})$, and vitamin $\mathrm{C}(\mu \mathrm{g} / \mathrm{l})$ and $\mathrm{E}(\mu \mathrm{g} / \mathrm{l})$ levels prior to intake of curcumin, one week after curcumin intake, and after 189 days in healthy controls.

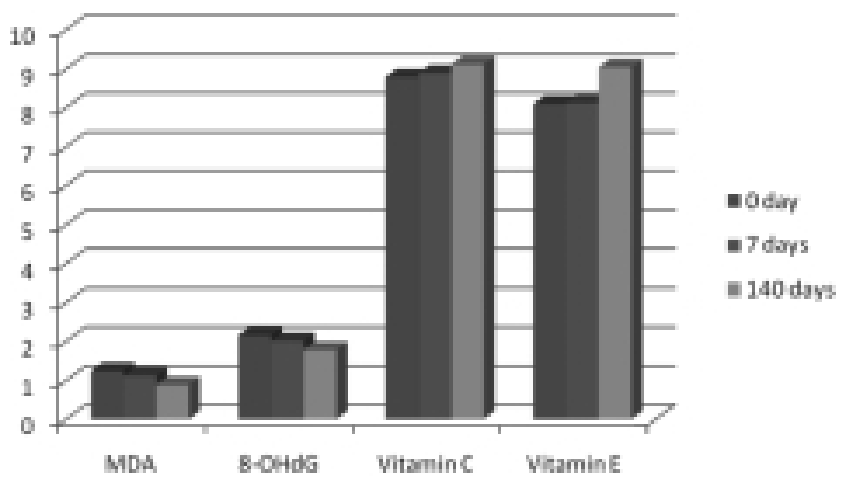

Fig. 6 Serum MDA ( $\mu \mathrm{mol} / \mathrm{l}), 8-\mathrm{OHdG}(\mathrm{ng} / \mathrm{ml})$, and vitamin $\mathrm{C}(\mu \mathrm{g} / \mathrm{l})$ and $\mathrm{E}(\mu \mathrm{g} / \mathrm{l})$ levels prior to intake of curcumin, one week after curcumin intake, and after clinical cure of oral leukoplakia. 


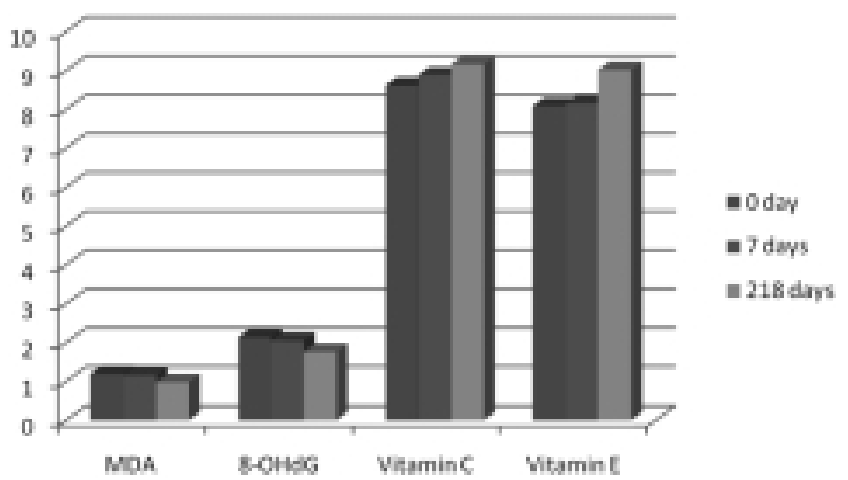

Fig. 7 Serum MDA ( $\mu \mathrm{mol} / \mathrm{l}), 8-\mathrm{OHdG}(\mathrm{ng} / \mathrm{ml})$, and vitamin $\mathrm{C}(\mu \mathrm{g} / \mathrm{l})$ and $\mathrm{E}(\mu \mathrm{g} / \mathrm{l})$ levels prior to intake of curcumin, one week after curcumin intake, and after clinical cure of oral submucous fibrosis.

\section{Discussion}

The goal of this study was to determine whether the antiprecancerous effects of curcumin are mediated through an antioxidant mechanism. Serum and salivary vitamin $\mathrm{C}$ and $\mathrm{E}$ levels were found to increase, while MDA and 8OHdG levels decreased in oral leukoplakia, submucous fibrosis and lichen-planus patients after intake of curcumin, as compared to pre-treatment levels. Furthermore, the changes in these values were found to be significant after clinical cure. Pain and lesion size diminished significantly in oral leukoplakia, submucous fibrosis and lichen-planus, while in submucous fibrosis, mouth opening recovered significantly. Our results suggest that curcumin significantly increases the local and systemic antioxidant status and the levels of vitamins $\mathrm{C}$ and $\mathrm{E}$, while it decreases the lipid peroxidation and DNA damage of patients with precancerous lesions. This could be due to curcumin-induced production of vitamins $\mathrm{C}$ and $\mathrm{E}$, and preventive DNA damage by decreasing the oxidation stress. This suggests that the anti-precancerous effects of curcumin are mediated through pro-oxidant and anti-oxidant pathways.

The mechanisms by which curcumin mediates its prooxidant effects remain unclear. It has been suggested that mitochondria play a role in curcumin-induced apoptosis. It is possible that curcumin activates the mitochondrial enzymes that lead to production of reactive oxygen species (ROS) (19-20). The induction of ROS by curcumin may occur through its interaction with thioredoxin reductase, thus altering its activity to NADPH oxidase, which could then lead to the production of ROS (21). There have also been reports suggesting that curcumin quenches ROS production and thus acts as an antioxidant, while others have reported that curcumin quenches ROS production at

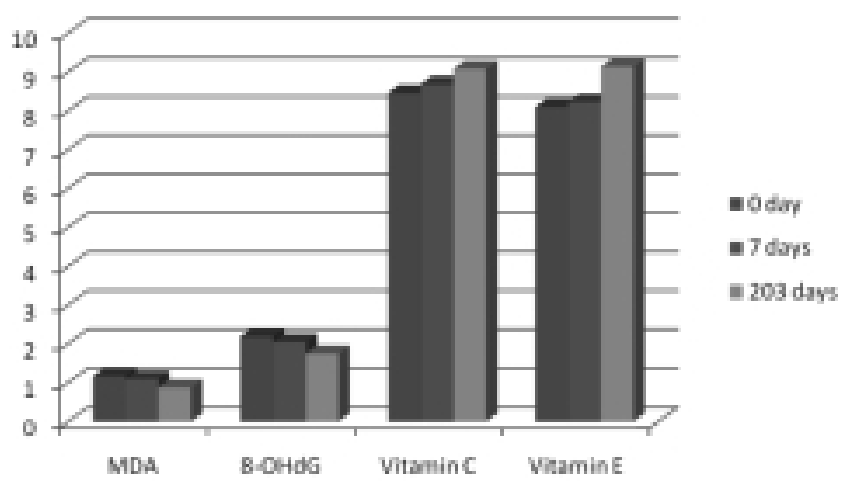

Fig. 8 Serum MDA ( $\mu \mathrm{mol} / \mathrm{l}), 8-\mathrm{OHdG}(\mathrm{ng} / \mathrm{ml})$, and vitamin $\mathrm{C}(\mu \mathrm{g} / \mathrm{l})$ and $\mathrm{E}(\mu \mathrm{g} / \mathrm{l})$ levels prior to intake of curcumin, one week after curcumin intake, and after clinical cure of oral lichen planus.

low concentrations and induces ROS production at high concentrations (22-23). It has also been stated that micronutrients enhance the levels of vitamins $\mathrm{A}$ and $\mathrm{C}$, as well as selenium, in the supplemented groups, with a concomittant regression of precancerous lesions present on the palate (24). We did not record any treatment-related toxic effects at doses up to $8 \mathrm{~g} / \mathrm{d}$, as reported previously (25). The oral leukoplakia, submucous fibrosis and lichen planus were cured in almost the same period of time. The antioxidant status of healthy subjects also improved with curcumin intake. Median salivary and serum MDA, 8$\mathrm{OHdG}$, vitamin $\mathrm{C}$ and $\mathrm{E}$ levels changed in precancerous patients before intake of curcumin and after clinical cure, and after 209 days in healthy subjects, although the changes were higher in precancerous patients. A significant correlation was observed in serum and salivary markers in all groups.

As saliva can be easily collected in a non-invasive manner, measurement of salivary disease biomarkers may prove vital in early detection of oral cancer risk. Moreover, salivary analysis for oral diagnosis may prove to be a cost-effective method for screening large populations. Further studies are required in larger samples in order to determine the relationship between curcumin, biomarkers and oral cancer, and to further contribute to the understanding of the mechanisms of action.

\section{References}

1. Parkin DM, Pisani P, Ferlay J (1993) Estimates of worldwide incidence of eighteen major cancers in 1985. Int J Cancer 54, 594-606.

2. World Health Organization (1984) Control of oral cancer in developing countries. A WHO meeting. 
Bull World Health Organ 62, 817-830.

3. Nair MK, Sankaranarayanan R (1991) Epidemiological leads to cancer control in India. Cancer Causes Control 2, 263-265.

4. Lippman SM, Hong WK (2001) Molecular markers of the risk of oral cancer. N Engl J Med 344, 1323 1326.

5. Reibel J (2003) Prognosis of oral pre-malignant lesions: significance of clinical, histopathological, and molecular biological characteristics. Crit Rev Oral Biol Med 14, 47-62.

6. Gupta PC, Bhonsle RB, Murti PR, Daftary DK, Mehta FS, Pindborg JJ (1989) An epidemiological assessment of cancer risk in oral precancerous lesions in India with special reference to nodular leucoplakia. Cancer 63, 2247-2252.

7. Allison P, Locber S, Feine JS (1998) The role of diagnostic delays in the prognosis of oral cancer: review of literature. Oral Oncol 34, 161-170.

8. Rai B, Kharb S, Jain R, Anand SC (2006) Salivary lipid peroxidation product malonaldehyde in various dental diseases. WJMS 1, 100-101.

9. Oberley LW, Oberley TD (1988) Role of antioxidant enzymes in cell immortalization and transformation. Mol Cell Biochem 84, 147-153.

10. Halliwell B (1994) Free radicals and antioxidants: a personal view. Nutr Rev 52, 253-265.

11. Dormandy TL (1983) An approach to free radicals. Lancet 2, 1010-1014.

12. Halliwell B (1996) Antioxidants in human health and disease. Annu Rev Nutr 16, 33-50.

13. Aggarwal S, Takada Y, Singh S, Myers JN, Aggarwal BB (2004) Inhibition of growth and survival of human head and neck squamous cell carcinoma cells by curcumin via modulation of nuclear factorkappaB signaling. Int J Cancer 111, 679-692.

14. Aggarwal BB, Kumar A, Bharti AC (2003) Anticancer potential of curcumin: preclinical and clinical studies. Anticancer Res 23, 363-398.

15. Sharma C, Kaur J, Shishodia S, Aggarwal BB, Ralhan R (2006) Curcumin down regulates smokeless tobacco-induced NF-kappaB activation and COX-2 expression in human oral premalignant and cancer cells. Toxicology 228, 1-15.

16. Buege JA, Aust SD (1978) Microsomal lipid peroxidation. Methods Enzymol 52, 302-310.

17. Nierenberg DW, Lester DC (1985) Determination of vitamins $\mathrm{A}$ and $\mathrm{E}$ in serum and plasma using a simplified clarification method and highperformance liquid chromatography. J Chromatogr 345, 275-284.

18. Toyokuni S, Tanaka T, Hattori Y, Nishiyama Y, Yoshida A, Uchida K, Hiai H, Ochi H, Osawa T (1997) Quantitative immunohistochemical determination of 8-hydroxy-2'-deoxyguanosine by a monoclonal antibody N45.1: its application to ferric nitrilotriacetate-induced renal carcinogenesis model. Lab Invest 76, 365-374.

19. Uddin S, Hussain AR, Manogaran PS, Al-Hussein K, Platanias LC, Gutierrez MI, Bhatia KG (2005) Curcumin suppresses growth and induces apoptosis in primary effusion lymphoma. Oncogene $24,7022-$ 7030 .

20. Atsumi T, Fujisawa S, Tonosaki K (2005) Relationship between intracellular ROS production and membrane mobility in curcumin- and tetrahydrocurcumin-treated human gingival fibroblasts and human submandibular gland carcinoma cells. Oral Dis 11, 236-242.

21. Fang J, Lu J, Holmgren A (2005) Thioredoxin reductase is irreversibly modified by curcumin: a novel molecular mechanism for its anticancer activity. J Biol Chem 280, 25284-25290.

22. Das KC, Das CK (2002) Curcumin (diferuloylmethane), a singlet oxygen $((1) \mathrm{O}(2))$ quencher. Biochem Biophys Res Commun 295, 6266.

23. Mishra S, Kapoor N, Mubarak Ali A, Pardhasaradhi BV, Kumari AL, Khar A, Misra K (2005) Differential apoptotic and redox regulatory activities of curcumin and its derivatives. Free Radic Biol Med 38, 13531360.

24. Krishnaswamy K, Prasad MP, Krishna TP, Annapurna VV, Reddy GA (2005) A case study of nutrient intervention of oral precancerous lesions in India. Eur J Cancer B Oral Oncol 31B, 41-48.

25. Cheng AL, Hsu CH, Lin JK, Hsu MM, Ho YF, Shen TS, Ko JY, Lin JT, Lin BR, Ming-Shiang W, Yu HS, Jee SH, Chen GS, Chen TM, Chen CA, Lai MK, Pu YS, Pan MH, Wang YJ, Tsai CC, Hsieh CY (2001) Phase I clinical trial of curcumin, a chemopreventive agent, in patients with high-risk or pre-malignant lesions. Anticancer Res 21, 28952900. 